\title{
Patterns of variation in reproductive parameters in Eurasian lynx (Lynx lynx)
}

\author{
Erlend B. Nilsen • John D. C. Linnell • John Odden • \\ Gustaf Samelius • Henrik Andrén
}

Received: 30 June 2011 / Accepted: 7 November 2011 / Published online: 27 November 2011

(C) The Author(s) 2012. This article is published with open access at Springerlink.com

\begin{abstract}
Detailed knowledge of the variation in demographic rates is central for our ability to understand the evolution of life history strategies and population dynamics, and to plan for the conservation of endangered species. We studied variation in reproductive output of 61 radio-collared Eurasian lynx females in four Scandinavian study sites spanning a total of 223 lynx-years. Specifically, we examined how the breeding proportion and litter size varied among study areas and age classes (2-year-old vs. $>2$-yearold females). In general, the breeding proportion varied between age classes and study sites, whereas we did not detect such variation in litter size. The lack of differences in litter sizes among age classes is at odds with most findings in large mammals, and we argue that this is because the level of prenatal investment is relatively low in felids compared to their substantial levels of postnatal care.
\end{abstract}

Keywords Demography · Reproduction · Carnivores · Litter size $\cdot$ Breeding proportion

\section{Introduction}

Describing and quantifying factors that contribute to variation in vital rates are crucial to our understanding of

Communicated by: Krzysztof Schmidt

E. B. Nilsen $(\bowtie) \cdot$ J. D. C. Linnell $\cdot$ J. Odden

Norwegian Institute for Nature Research,

7485 Trondheim, Norway

e-mail: erlend.nilsen@nina.no

G. Samelius $\cdot H$. Andrén

Grimsö Wildlife Research Station, Department of Ecology,

Swedish University of Agricultural Sciences,

73091 Riddarhyttan, Sweden the evolution of life histories, population dynamics, and to our ability to understand factors affecting population viability in conservation contexts (Kerley et al. 2003). In long-lived species with long generation times, such as large herbivores and large carnivores, the functional relationship between long-term population growth and adult survival is stronger than that for recruitment (Gaillard et al. 2000; Bielby et al. 2007; Nilsen et al. 2009). However, the impact of a vital rate on observed variation in population growth rate is the product of the elasticity of population growth rate and the coefficient of variation in that parameter as well as the actual variation in that parameter (Coulson et al. 2005; Horvitz et al. 1997). As variation usually reduces the longterm growth rate of populations (Tuljapurkar and Orzack 1980), reproductive output typically shows more pronounced variation across time and space than survival rates (Gaillard et al. 2000; Gaillard and Yoccoz 2003). Understanding sources of variation in reproductive output is therefore of crucial importance for successful conservation and management planning.

Variation in fertility rates is caused by variation in a sequence of factors that together define fertility. For example, if defining fertility as the number of offspring per female at birth (Caswell 2001), fertility is given by the product between the proportion of females that breed in a given year and the litter sizes of breeding females. In polytocous species (such as the Eurasian lynx, Lynx lynx, which is studied here) these rates might vary independently of each other. Both phylogenetic and physiological constraints, and adaptive allocation to current reproduction relative to survival and future fitness prospects (Stearns 1992) might induce variation in reproductive output.

In long-lived iteroparous species, reproductive output is often strongly age-dependent (Gaillard et al. 1992), with a lower reproductive output in first-time breeders (Forslund 
and Part 1995). Such patterns could arise due to several factors, both due to constraints in the skills of young animals (Forslund and Part 1995; Rutz et al. 2006) and due to restraints (Curio 1983); i.e., young animals might put less effort into breeding because reproductive effort might increase mortality and/or reduce future reproductive success (Stearns 1992). Furthermore, varying ecological conditions might cause fertility to vary also within age classes. In general, low food availability and high population densities have been shown to reduce fertility rates especially among young individuals (Gaillard et al. 1998b; Gaillard et al. 2000). The relationship between fertility rate and ecological conditions is often more pronounced in certain stages of the life cycle, and it is generally acknowledged that reproductive output among young females is among the first traits affected when ecological conditions get harsh (Gaillard et al. 2000). Finally, as late gestation and lactation are commonly regarded as costly, spontaneous or selective abortion (as well as perinatal survival) might result in differences in the proportion of pregnant females that give birth to viable young, despite no differences in the proportion that implant and become pregnant. If such early mortality/abortion is not independent among litter mates, this should create variation in breeding proportion rather than litter sizes.

Eurasian lynx have a wide distribution, covering much of the boreal forest in Eurasia (von Arx et al. 2004). The combined population from Norway and Sweden is $>2,000$ individuals implying a high degree of viability (Andrèn and Liberg 2008; Brøseth and Tovmo 2011). However, the species is associated with widespread conflicts (with livestock breeders and hunters) and is therefore subject to intensive hunting and lethal control (Nilsen et al., online early), as well as poaching (Andrèn et al. 2006; Linnell et al. 2010). Thus, lynx is a species of conservation concern subject to active management in Scandinavia and its conservation requires solid biological knowledge. This includes high-quality demographic data to be used when setting hunting quotas and when monitoring the population size based on surveys of lynx family groups (i.e., females with dependent kittens) (Linnell et al. 2010; Andrèn et al. 2002). To date, the only available published data on lynx reproductive rates are from a reintroduced population in the Jura Mts. (Breitenmoser-Würsten et al. 2007), captive lynx (Henriksen et al. 2005), and some older Norwegian data extracted from shot lynx (Kvam 1991). Based on an exceptionally large data base of radio-collared Eurasian lynx from four study sites in Scandinavia $(n=61$ female lynx followed for a total of 223 lynx years) we examined how breeding proportion and litter size varied among age classes (2-year-old vs. >2-year-old females) and between lynx populations across a range of ecological settings. Based on available literature from large mammals (see above sections) we expected that (a) the proportion of young females producing offspring should be higher in the southern populations with higher prey densities, and (b) a lower proportion of young compared to older females should produce offspring. Furthermore, we expected that c) the litter sizes of prime aged females should be larger than those of young females.

\section{Methods}

Study areas

This study was based on individual data obtained from radio-collared lynx in four study areas in Scandinavia: Sarek and Bergslagen in Sweden, Hedmark and Akershus in Norway (Table 1; Fig. 1). The northernmost study area is partly located within the Sarek National Park around Kvikkjokk in the county of Norrbotten $\left(67^{\circ} 00^{\prime} \mathrm{N}, 17^{\circ} 40^{\prime} \mathrm{E}\right)$ and consists of a mixture of coniferous forests, mountain birch Betula sp. forest and alpine tundra in mountainous terrain. The central area is situated in the county of Hedmark in southeastern Norway $\left(61^{\circ} 15^{\prime} \mathrm{N}, 11^{\circ} 30^{\prime} \mathrm{E}\right)$. The topography of

Table 1 Basic description of the study sites

\begin{tabular}{|c|c|c|c|c|}
\hline Study site & Sarek (Sweden) & Hedmark (Norway) & Akershus (Norway) & Bergslagen (Sweden) \\
\hline Latitude & $67^{\circ} \mathrm{N}$ & $61^{\circ} 30^{\prime} \mathrm{N}$ & $59^{\circ} 46^{\prime} \mathrm{N}$ & $59^{\circ} 30^{\prime} \mathrm{N}$ \\
\hline Habitat & $\mathrm{BF} / \mathrm{LA} / \mathrm{HA}$ & $\mathrm{BF}$ & $\mathrm{BF}$ & $\mathrm{BF}$ \\
\hline Wild prey ${ }^{a}$ & $\begin{array}{l}\text { Ptarmigan, mountain } \\
\text { hare, capercaille, } \\
\text { black grouse }\end{array}$ & $\begin{array}{l}\text { Roe deer,* red deer, wild } \\
\text { reindeer, mountain hare, } \\
\text { capercaille, black grouse }\end{array}$ & $\begin{array}{l}\text { Roe deer,* mountain } \\
\text { hare, capercaille, } \\
\text { black grouse }\end{array}$ & $\begin{array}{l}\text { Roe deer,* mountain } \\
\text { hare, brown hare, } \\
\text { capercaille, black grouse }\end{array}$ \\
\hline Domestic prey & Semidomestic reindeer* & Sheep & Sheep & \\
\hline Density of main prey ${ }^{\mathrm{b}}$ & $1-2 / \mathrm{km}^{2}$ & $0.3 / \mathrm{km}^{2}$ & $1-10 / \mathrm{km}^{2}$ & $3-4 / \mathrm{km}^{2}$ \\
\hline
\end{tabular}

$B F$ boreal forest, $L A$ low alpine (above the treeline), $H A$ high alpine

${ }^{a}$ The main prey species in each study area is marked with an asterisk

${ }^{\mathrm{b}}$ References for densities of main prey: Danell et al. (2006) for Sweden and Linnell et al. (2007) for Norway 


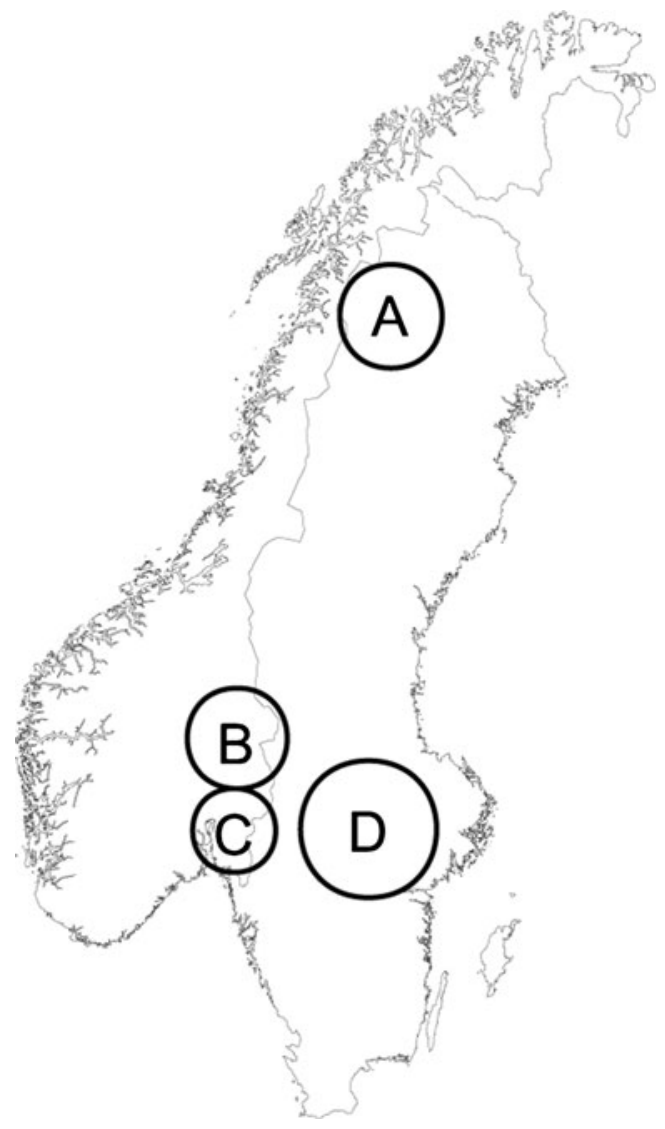

Fig. 1 Map showing the location of the study sites across Scandinavia. a Sarek, b Hedmark, c Akershus, d Bergslagen

the area consists of several parallel river valleys running from north to south, and about $72 \%$ of the area consists of coniferous forest. The Akershus study area $\left(59^{\circ} 45^{\prime} \mathrm{N}, 11^{\circ} 15^{\prime} \mathrm{E}\right)$ is situated around the Norwegian capital, Oslo, and is similar to the Hedmark area although the proportion of farmland and human density is much higher and the topography is less hilly. The Bergslagen study area is located around Grimsö wildlife research station $\left(59^{\circ} 30^{\prime} \mathrm{N}, 15^{\circ} 30^{\prime} \mathrm{E}\right)$ in southcentral Sweden. The area is dominated by coniferous forest, and the proportion of agricultural land is higher in the southern parts (about 20\%) and decreases towards the northern parts $(<1 \%$ of the area). Roe deer (Capreolus capreolus) are the main prey in the Hedmark, Akershus and Bergslagen study areas, while semi-domestic reindeer (Rangifer tarandus) are the main prey in the Sarek area where roe deer are absent (Andrèn et al. 2006; Odden et al. 2006). In addition, a range of smaller species such as capercaille (Tetrao urogallus), black grouse (T. tetrix), mountain hares (Lepus timidus) and red foxes (Vulpes vulpes) are available in all sites, together with domestic sheep in the Norwegian sites during summer (see Andrèn et al. 2002; Andrèn et al. 2006; Linnell et al. 2001).
Field procedures

This project is part of the large scale research project Scandlynx (http://scandlynx.nina.no/) that coordinates research efforts on lynx in Norway and Sweden. Lynx were captured using several methods, including darting from helicopters, box-traps, foot-snares placed at fresh kills, and by using dogs to chase lynx into trees. The captured lynx were immobilized and equipped with a radio-collar (either VHF or GPS) or an implanted radio transmitter, usually with a mortality function. The handling protocol for lynx has been examined by both the Swedish and the Norwegian Experimental Animal Ethics Committee and fulfils their ethical requirements for research on wild animals. For further description of capture techniques, see Andrèn et al. (2002) and Arnemo et al. (1999, 2006).

The lynx were radio-tracked at least two to four times per month, but normally more often. In May and June, the reproductive status of all female lynx was examined by more frequent localisation of radio-marked females from the ground and or the air, and counting the kittens in the natal lair if movement data indicated that she had given birth (Schmidt 1998). Field protocols varied between study areas (the wilderness nature of the Sarek site imposed logistical challenges) and with time (as VHF telemetry gave way to GPS technology with UHF and GSM downloads). Potentially reproductive females were tracked as often as possible during the birth period in May and early June. In most areas, we radio-tracked female lynx several times per week during the birth period. This sampling protocol would have made it difficult to detect females who gave birth and subsequently lost their kittens in the first few days of life, so our estimate of reproductive rates refers to those that had kittens that lived to at least 2 weeks of age. However, because females adopt a central place foraging behavior centered on a natal lair for the first 6-8 weeks of the kittens lives it was almost impossible to have failed to detect a reproductive event where kittens survived the perinatal period. Once reproduction was established we visited the natal lair site to count, weight, sex and mark (usually with microchips and/or tattoos, but occasionally with intraperitoneal implants). Our visits were normally conducted when kittens were between 2 and 6 weeks of age. The number of reproductive events and female lynx included in the analysis in this study is reported in Table 2.

The age at capture was known for animals originally marked in their lairs, whereas we classed previously unmarked animals that were captured during winter as subadult $(<18$ months old) and adult $(>18$ months old) based on whether they were structurally fully grown. A large portion of animals were captured in spring when still travelling with their mothers and $<1$ year old, which further helped to determine the age of animals. In addition, age was 
Table 2 Number of reproductive events and number of female lynx included in this study

\begin{tabular}{lrccl}
\hline & 2 years & $>2$ years & Lynx individuals & Years \\
\hline Sarek & 13 & 92 & 22 & $1994-2007$ \\
Hedmark & 4 & 38 & 11 & $1996-2006$ \\
Akershus & 4 & 14 & 6 & $2001-2006$ \\
Bergslagen & 19 & 39 & 20 & $1997-2006$ \\
\hline
\end{tabular}

also in many cases determined retrospectively post mortem by counting incremental lines in the tooth cementum (see Kvam 1984) when animals died or were shot.

\section{Statistical analysis}

We used generalized linear mixed effects models implemented with the lmer function in library lme4 (Bates et al. 2010) in software R 2.12.1 (R Development Core Team 2010) to examine patterns of variation in lynx breeding performance. Specifically, we examined how the breeding proportion and litter size of lynx varied among study sites and age classes. In the models examining patterns in breeding proportion, we used a binomial error term for the fixed components, whereas we used a Poisson error term when the focus was on litter sizes. We assessed models with the main effects of study area and age class, as well as their interaction, and selected the most parsimonious model in the set based on Akaike's Information Criterion (AIC) (Burnham and Anderson 2002). To assess the relative support for each model, we also computed Akaike weights for each model in the set giving a measure of relative support for each model among the considered candidate models. To examine the patterns of age dependency in reproductive output, we used both a two age-class model contrasting young females ( 2 years of age) with older females ( $>2$ years of age), and a full-age model including only females of known age and older than 2 years.

Table 3 Breeding proportion and litter size of lynx in the study sites included in this study, estimated with generalized linear mixed effects models with individual as a random factor (to account for pseudor-

\section{Results}

There was substantial variation between study areas and age classes in the proportion of lynx females that gave birth (Tables 3 and 4), and the model that best described the variation in breeding proportion included the main effects of study area and age class (Table 3). In general, the proportion of 2-year-old lynx females that gave birth was lower than that of the older females (Table 3). Among females in the older age class (i.e., $>2$ years old) there was no indication for variation in the proportion of females that gave birth with increasing age in any study area or for all study areas combined ( $\triangle \mathrm{AIC}=1.53$ for the model including age and $\triangle \mathrm{AIC}=0.86$ for the model including a squared effect of age; the null model included only the intercept).

In general, litter size did not vary between study sites or age classes (Tables 3 and 4). Similarly, among females in the oldest age class (i.e., $>2$ years old), there was no indication for any difference in litter size $(\triangle \mathrm{AIC}=1.91$ for the model including age; the null model included only the intercept).

\section{Discussion}

In this paper, we explored the patterns of spatial variation in reproductive rates in Eurasian lynx using a large sample of radio-collared lynx. We show that, in general, (1) litter size was less variable than the proportion of females that gave birth, (2) there were substantial differences between sites in the proportion of females that gave birth, and (3) that the variation in the breeding proportion was particularly pronounced among young females (2 years old).

The proportion of young females (i.e., 2 years old) that produced a litter varied markedly between our study populations. Such patterns in other species have often been linked to the prevailing ecological conditions (Gaillard et

eplication) and the two-way interaction between age class and study area as fixed effects

\begin{tabular}{|c|c|c|c|c|}
\hline & \multicolumn{2}{|c|}{ Breeding proportion } & \multicolumn{2}{|l|}{ Litter size } \\
\hline & 2 years old & $>2$ years old & 2 years old & $>2$ years old \\
\hline Sarek & $0.22(0.06-0.53)$ & $0.76(0.62-0.87)$ & $1.99(1.30-3.04)$ & $2.09(1.90-2.30)$ \\
\hline Hedmark & $0.40(0.09-0.81)$ & $0.69(0.53-0.81)$ & $2.09(1.13-3.87)$ & $2.10(1.83-2.41)$ \\
\hline Akershus & $0.50(0.10-0.90)$ & $0.81(0.55-0.94)$ & $1.90(1.62-5.18)$ & $1.95(1.35-2.81)$ \\
\hline Bergslagen & $0.74(0.49-0.89)$ & $0.90(0.76-0.96)$ & $2.34(1.94-2.81)$ & $2.37(2.10-2.69)$ \\
\hline
\end{tabular}

When analysing the breeding proportion a binomial error structure and logit link were used, whereas a Poisson error structure and log link were used to model litter sizes. Estimates are given as mean $(95 \% \mathrm{CL})$ 
Table 4 AIC values for models evaluating the variation in lynx breeding proportion and litter sizes in the study sites included in this study

\begin{tabular}{|c|c|c|c|c|c|c|}
\hline & \multicolumn{3}{|c|}{ Breeding proportion } & \multicolumn{3}{|c|}{ Litter size } \\
\hline & AIC & $\Delta \mathrm{AIC}$ & $w_{i}$ & AIC & $\Delta \mathrm{AIC}$ & $w_{i}$ \\
\hline Intercept & 292.70 & 16.70 & 0.000 & 45.70 & $\mathbf{0}$ & 0.644 \\
\hline Study area & 291.50 & 15.5 & 0.000 & 50.52 & 4.82 & 0.058 \\
\hline Ageclass & 284.10 & 8.1 & 0.016 & 47.40 & 1.70 & 0.275 \\
\hline Study area + Ageclass & 276.00 & $\mathbf{0}$ & 0.890 & 52.48 & 6.78 & 0.022 \\
\hline Study area $\times$ Ageclass $^{a}$ & 280.50 & 4.5 & 0.094 & 57.80 & 12.1 & 0.002 \\
\hline
\end{tabular}

All models are generalized linear mixed effects models, with lynx identity fitted as random factor (intercept). The selected models (i.e., those with the lowest AIC values) are marked in bold

${ }^{a}$ Model includes main effects of study area and age class, as well as their interaction)

al. 1992). For instance, it is generally acknowledged that age at maturity is one of the first life history traits to change when conditions switch from favorable to unfavorable (Eberhardt 1977, 2002). In general the breeding proportion was highest in the southernmost study population (Bergslagen), and lowest in the northernmost population (Sarek), with both the Norwegian populations showing intermediate values. Supporting these findings, we have previously found that the proportion of 1.5 -year-old females that ovulate (i.e., that are sexually mature) was generally lower in the northernmost areas (Nilsen et al. 2010). Consequently, on a broad scale the patterns might indicate a slower life cycle in more extreme northern environments. Previous studies on lynx have indicated a clear effect of body mass on age at maturity (Nilsen et al. 2010). It is therefore possible that different maturation rates between sites will result in differential allocation to reproduction among yearling lynx in the different study areas (restraint hypothesis; Curio 1983), due to different growth rates affecting patterns of maturation in the populations. Although speculative, the different patterns in breeding proportions assessed by litter size observations and ovulation rates reported by Nilsen et al. (2010) suggest that the geographical variation in the breeding proportion may be caused by differences in feeding conditions and growth rates among areas. This theory is supported by the fact that body size and body mass of lynx in southern Sweden were related to roe deer availability during the first year of life (Yom-Tov et al. 2010). The lower reproductive rates in the Sarek study area may reflect their dependence on migratory semi-domestic reindeer as prey (Mattisson et al. online early; Pedersen et al. 1999), while the lynx are resident (Danell et al. 2006) and thus face a high degree of seasonality in their access to prey.

While there was a clear difference between females that were 2 years old and those that were older in the proportion that gave birth, litter sizes did not differ between these age classes, indicating that females that mature early invest relatively heavily in their first litter (see also Nilsen et al. 2010). This might be somewhat surprising given the potentially high costs of reproduction at low age in carnivores (Proaktor et al. 2007). In fact, the lack of agedependency in litter sizes is unusual for polytocous species, where litter sizes are generally higher for multiparous than primiparous females (Ericsson et al. 2001; Forslund and Part 1995). Moreover, litter sizes were very similar across study sites, but our data did not allow us to investigate whether early mortality happened before or after parturition, as we only had measures of litter size from when kittens were about 1 month old (see Methods). The fact that litter sizes did not vary between study sites or age classes, might indicate that whenever early mortality occurred, the fate of litter mates were dependent on each other so that the mean litter size did not change. If they were, one would expect smaller litter sizes in areas with low breeding proportion. Such family effects in early survival have been documented in studies of other species and greatly increase the variation in reproductive success among individuals (Pettorelli and Durant 2007; Gaillard et al. 1998a; Panzacchi et al. 2009).

In summary, fertility is the product of the proportion of females that give birth and litter size. Different ecological and physiological process might cause variation in these traits. Specifically, our study suggests that variation in fecundity between sites and age classes was mostly caused by variation in the proportion of females that gave birth, whereas litter sizes were remarkably constant across sites and age classes. As expected from theory, between-site variation in breeding proportion was higher among young females than among older females. The reproductive parameters recorded in this study were very similar to those recorded from both wild lynx in the Jura Mts. (Breitenmoser-Würsten et al. 2007) and captive (Henriksen et al. 2005) populations of lynx from across European zoos, although the litter size decreased in the Jura Mts. population when there was a lack of mature males 
(Breitenmoser-Würsten et al. 2007). We doubt if this effect was present in our study sites. Although all our study areas were subject to lynx hunting and/or poaching in the period immediately prior to the mating season, the study areas are all imbedded in a large and continuous population with continuous habitat. This combined with the fact that harvest is usually evenly dispersed over large areas minimizes the chances of all males being removed from a given area and allows neighboring male lynx to expand their ranges to cover potentially receptive females. Furthermore, there are a large number of floating, non-territorial individuals who can rapidly occupy vacant territories (Samelius et al. 2011). The impression from these studies that span autochthonous, reintroduced, and captive populations is that lynx reproduction is remarkably constant, with the only substantial source of regional variation being caused by the proportion of 2-year-old females that breed.

Acknowledgements The study was funded by the Swedish Environmental Protection Agency, the Norwegian Directorate for Nature Management, the Research Council of Norway, the European Union's 7th Framework Programme, the World Wide Fund for Nature (Sweden), the Swedish Research Council for Environment, Agricultural Sciences and Spatial Planning (Formas), the Swedish Association of Hunting and Wildlife Management, the private foundations "Olle och Signhild Engkvists Stiftelser", "Marie- Claire Cronstedts Stiftelse", and the Nature Protection Division of the County Governor's Office for Oslo \& Akershus, Østfold and, Hedmark. We are grateful to the many people who have assisted with field work through the years of this project's life.

Open Access This article is distributed under the terms of the Creative Commons Attribution Noncommercial License which permits any noncommercial use, distribution, and reproduction in any medium, provided the original author(s) and source are credited.

\section{References}

Andrèn H, Liberg O (2008) The Swedish lynx population 20042008. Report Grimsö Wildlife Research Station. Swedish Wildlife Damage Centre, Swedish University of Agricultural Sciences

Andrèn $\mathrm{H}$, Linnell JDC, Liberg $\mathrm{O}$, Ahlqvist $\mathrm{P}$, Andersen R, Danell A, Franzen R, Kvam T, Odden J, Segerstrom P (2002) Estimating total lynx Lynx lynx population size from censuses of family groups. Wildl Biol 8(4):299-306

Andrèn $\mathrm{H}$, Linnell JDC, Liberg $\mathrm{O}$, Andersen $\mathrm{R}$, Danell $\mathrm{A}$, Karlsson J, Odden J, Moa PF, Ahlqvist P, Kvam T, Franzen $R$, Segerstrom P (2006) Survival rates and causes of mortality in Eurasian lynx (Lynx lynx) in multi-use landscapes. Biol Conserv 131(1):23-32

Arnemo JM, Linnell JDC, Wedul SJ, Ranheim B, Odden J, Andersen $\mathrm{R}$ (1999) Use of intraperitoneal radio-transmitters in lynx Lynx lynx kittens: anaesthesia, surgery and behaviour. Wildl Biol 5 (4):245-250

Arnemo JM, Ahlqvist P, Andersen R, Berntsen F, Ericsson G, Odden J, Brunberg S, Segerstrom P, Swenson JE (2006) Risk of capturerelated mortality in large free-ranging mammals: experiences from Scandinavia. Wildl Biol 12(1):109-113
Bates D, Maechler M, Bolker B (2010) lme4: linear mixed-effects models using S4 classes. R package version 0.999375-41. http:// CRAN.R-project.org/package=lme4

Bielby J, Mace GM, Bininda-Emonds ORP, Cardillo M, Gittleman JL, Jones KE, Orme CDL, Purvis A (2007) The fast-slow continuum in mammalian life history: an empirical reevaluation. Am Nat 169(6):748-757

Breitenmoser-Würsten C, Vandel JM, Zimmermann F, Breitenmoser U (2007) Demography of lynx Lynx lynx in the Jura Mountains. Wildl Biol 13(4):381-392

Brøseth H, Tovmo M (2011) Antall familiegrupper, bestandsestimat og bestandsutvikling for gaupe i Norge i 2011. NINA Report 741

Burnham KP, Anderson DR (2002) Model selection and multimodel inference: a practical information-theoretic approach, 2nd edn. Springer-Verlag, New York

Caswell H (2001) Matrix population models: construction, analysis and interpretation, 2nd edn. Sinauer Associates Inc., Massachusetts

Coulson T, Gaillard JM, Festa-Bianchet M (2005) Decomposing the variation in population growth into contributions from multiple demographic rates. J Anim Ecol 74(4):789-801

Curio E (1983) Why do young birds reproduce less well? Ibis 125:400-404

Danell AC, Andren H, Segerstrom P, Franzen R (2006) Space use by Eurasian lynx in relation to reindeer migration. Can J Zool-Rev Can Zool 84(4):546-555

Eberhardt LL (1977) Optimal policies for conservation of large mammals with special reference to marine ecosystems. Environ Conserv 4:202-212

Eberhardt LL (2002) A paradigm for population analysis of long-lived vertebrates. Ecology 83(10):2841-2854

Ericsson G, Wallin K, Ball JP, Broberg M (2001) Age-related reproductive effort and senescence in free-ranging moose, Alces alces. Ecology 82(6):1613-1620

Forslund P, Part T (1995) Age and reproduction in birds - hypothesis and tests. Trends Ecol Evol 10(9):374-378

Gaillard JM, Yoccoz NG (2003) Temporal variation in survival of mammals: a case of environmental canalization? Ecology 84 (12):3294-3306

Gaillard JM, Sempere AJ, Boutin JM, Vanlaere G, Boisaubert B (1992) Effects of age and body-weight on the proportion of females breeding in a population of roe deer (Capreolus capreolus). Can J Zool 70(8):1541-1545

Gaillard JM, Andersen R, Delorme D, Linnell JDC (1998a) Family effects on growth and survival of juvenile roe deer. Ecology 79 (8):2878-2889

Gaillard JM, Festa-Bianchet M, Yoccoz NG (1998b) Population dynamics of large herbivores: variable recruitment with constant adult survival. Trends Ecol Evol 13(2):58-63

Gaillard JM, Festa-Bianchet M, Yoccoz NG, Loison A, Toigo C (2000) Temporal variation in fitness components and population dynamics of large herbivores. Annu Rev Ecol Syst 31:367-393

Henriksen HB, Andersen R, Hewison AJM, Gaillard JM, Bronndal M, Jonsson S, Linnell JDC, Odden J (2005) Reproductive biology of captive female Eurasian lynx, Lynx lynx. Eur J Wildl Res 51 (3): 151-156

Horvitz C, Schemske DW, Caswell H (1997) The relative "importance" of life-history stages to population growth: prospective and retrospective analyses. In: Tuljapurkar S, Caswell $\mathrm{H}$ (eds) Structured population models in marine, terrestrial and freshwater systems. Chapman \& Hall, New York, pp 247-271

Kerley LL, Goodrich JM, Miquelle D, Smirnov EN, Quigley H, Hornocker MG (2003) Reproductive parameters of wild female Amur (Siberian) tigers (Panthera tigris altaica). J Mammal 84:288-298 
Kvam T (1984) Age determination in European lynx Lynx lynx by incremental lines in tooth cementum. Acta Zool Fenn 171:221-223

Kvam T (1991) Reproduction in the European lynx, Lynx lynx. Z Saugetierkd-Int J Mamm Biol 56:146-158

Linnell JDC, Andersen R, Kvam T, Andren H, Liberg O, Odden J, Moa PF (2001) Home range size and choice of management strategy for lynx in Scandinavia. Environ Manag 27(6):869-879

Linnell JDC, Odden J, Andren H, Liberg O, Andersen R, Moa P, Kvam T, Broseth H, Segerstrom P, Ahlqvist P, Schmidt K, Jedrzejewski W, Okarma H (2007) Distance rules for minimum counts of Eurasian lynx Lynx lynx family groups under different ecological conditions. Wildl Biol 13(4):447-455

Linnell JDC, Brøseth H, Odden J, Nilsen EB (2010) Sustainably harvesting a large carnivore? Development of Eurasian lynx populations in Norway during 160 years of shifting policy. Environ Manag 45:1142-1154

Mattisson J, Odden J, Nilsen EB, Linnell JDC, Persson J, Andrén H Factors affecting Eurasian lynx kill rates on semi-domestic reindeer in northern Scandinavia: can ecological research contribute to the development of a fair compensation system? Biol Conserv. Online early. doi:10.1016/j.biocon.2011.09.004

Nilsen E, Brøseth H, Odden J, Linnell JDC Quota hunting of Eurasian lynx in Norway: patterns of hunter selection, hunter efficiency and monitoring accuracy. Eur J Wildl Res:1-9. Online early. doi:10.1007/s10344-011-0585-Z

Nilsen EB, Gaillard JM, Andersen R, Odden J, Delorme D, van Laere G, Linnell JDC (2009) A slow life in hell or a fast life in heaven: demographic analyses of contrasting roe deer populations. J Anim Ecol 78(3):585-594. doi:10.1111/j.1365-2656.2009.01523.x

Nilsen EB, Brøseth H, Odden J, Linnell JDC (2010) The cost of maturing early in a solitary carnivore. Oecologia 164(4):943948. doi:10.1007/s00442-010-1713-2

Odden J, Linnell JDC, Andersen R (2006) Diet of Eurasian lynx, Lynx lynx, in the boreal forest of southeastern Norway: the relative importance of livestock and hares at low roe deer density. Eur J Wildl Res 52(4):237-244
Panzacchi M, Linnell JDC, Odden M, Odden J, Andersen R (2009) Habitat and roe deer fawn vulnerability to red fox predation. J Anim Ecol 78(6):1124-1133. doi:10.1111/j.13652656.2009.01584.x

Pedersen VA, Linnell JDC, Andersen R, Andren H, Linden M, Segerstrom P (1999) Winter lynx Lynx lynx predation on semidomestic reindeer Rangifer tarandus in northern Sweden. Wildl Biol 5(4):203-211

Pettorelli N, Durant SM (2007) Longevity in cheetahs: the key to success? Oikos 116(11):1879-1886. doi:10.1111/j.2007.00301299.16187.x

Proaktor G, Milner-Gulland EJ, Coulson T (2007) Age-related shapes of the cost of reproduction in vertebrates. Biol Lett 3(6):674-677. doi:10.1098/rsbl.2007.0376

R Development Core Team (2010) R: a language and environment for statistical computing. R Foundation for statistical computing, Vienna

Rutz C, Whittingham MJ, Newton I (2006) Age-dependent diet choice in an avian top predator. Proc R Soc B Biol Sci 273(1586):579586. doi:10.1098/rspb.2005.3353

Samelius G, Andrèn H, Liberg O, Linnell JDC, Odden J, Ahlqvist P, Segerstroem P, Sköld K (2011) Spatial and temporal variation in natal dispersal by Eurasian lynx in Scandinavia. J Zool. doi:10.1111/j.1469-7998.2011.00857.x, Printed Online

Schmidt K (1998) Maternal behaviour and juvenile dispersal in the Eurasian lynx. Acta Theriol 43:391-408

Stearns SC (1992) The evolution of life histories, 1st edn. Oxford University Press, Oxford

Tuljapurkar SD, Orzack SH (1980) Population dynamics in variable environments: 1. Long-run growth rates and extinction. Theor Popul Biol 18(3):314-342

von Arx M, Breitenmoser-Wursten C, Zimmermann F, Breitenmoser U (2004) Status and conservation of the Eurasian lynx (Lynx lynx) in Europe in 2001. KORA Bericht, vol 19

Yom-Tov Y, Kjellander P, Yom-Tov S, Mortensen P, Andrèn H (2010) Body size in the Eurasian lynx in Sweden: dependence on prey availability. Pol Biol 33:505-513 